\title{
DEVELOPMENT AND PERFORMANCE EVALUATION OF SMALL SCALE RICE PUFFING MACHINE
}

\section{POORNIMA, NAGARATNA, P. JAYRAJ, SIDDESH MARIHONNAPANNAVARA \& K. T. RAMAPPA}

College of Agricultural Engineering, Raichur, University of Agricultural Sciences, Raichur, Karnataka, India

The machine consists of blower unit, heating unit, container, casing, wooden platform and power consumption. Two types of power transmission was used in the developed machine, one from electric motor of $0.25 \mathrm{hp}$ capacity for blower and the other one for heating coil connected directly to electric source. After achieving 220-250 ${ }^{\circ} \mathrm{C}$ temperature in the container, the specified feed rate of conditioned rice in to the container will result in puffed rice within a short span of around 10-12 sec. The capacity of the small scale rice puffing machine ranges between $4-5 \mathrm{~kg} / \mathrm{h}$.

KEYWORDS: Puffed Rice \& Puffing Machine
\end{abstract}

Received: Jul 10 12, 2017; Accepted: Jul 31, 2017; Published: Aug 16, 2017; Paper Id.: IJASRAUG201798

\section{INTRODUCTION}

Paddy (Oryza sativa L.) is second largest major cereal crop a member of grass family (Graminaceae), which produces starchy seeds. Rice is used as an important staple food by the people in many parts of the world after wheat. Puffed rice is a popular snack food product in India and has been widely produced for centuries. Reliable figures on the volume of the puffed rice production in India are not available. But it has been estimated that about $10 \%$ of rice is converted into rice food snack items. At present the puffed rice is made at cottage and semi-mechanized levels and mostly in a batch type unit.

The Food processing industry has an important role to play in linking the farmers to the final consumers in the domestic as well as the international markets. Food processing combined with marketing has the potential of solving the basic problems of agricultural surpluses, wastages, rural jobs, and better remuneration to the growers. In the next ten years, food production is expected to double. These produces, if processed and marketed smartly, can make India a leading food supplier of the world. India with a population of 1.08 billion (growing at about 1.7 $\%$ per annum) provides a large and growing market for food products. Food products are the single largest component of private consumption expenditure, accounting for as much as $49 \%$ of the total spending. Furthermore, the upward mobility of income classes and increasing need for convenience and hygiene is driving demand for (a) perishables and non food staples and (b) processed foods. The processed food industry should introduce innovative new products of high quality at low cost in small package sizes in ready to eat format to cash on this booming opportunity.

\section{REVIEW OF LITERATURE}

Chandrasekhar and Chattopadhyay (1989) developed the pneumatic rice puffing machine for increasing the production capacity of puffed rice. The physical properties of the rice grains and other fluidization parameters, necessary for this study was experimentally determined. The surface heat transfer coefficient in case of hot air 
fluidized bed puffing was found to be $155.39 \mathrm{~W} / \mathrm{m}^{2} \mathrm{~K}$. The calculated grain surface temperature for puffing was about $170^{\circ} \mathrm{C}$ and this did not vary significantly for experimental puffing air temperatures ranging from $200^{\circ} \mathrm{C}$ to $270^{\circ} \mathrm{C}$. the air temperature ranging from $240^{\circ} \mathrm{C}$ to $270^{\circ} \mathrm{C}$ with corresponding exposure time of $9.7 \mathrm{~s}$ to $7 \mathrm{~s}$ was found to be optimum for higher expansion ratio ( 8.5 to 10 ) and better color of the product.

Malleshi and Desikachar (1981) studied the effect of various processing conditions to determine the optimum conditions. Optimal conditions for puffing of ragi were moistening to 19 per cent moisture and equilibration for $4 \mathrm{hr}$, followed by puffing in sand medium to $270^{\circ} \mathrm{C}$. Wide varietal variation has been found in the puffing quality, among the fourteen varieties studied. No consistent relationship was observed between the grain in amylose, protein content or thickness of bran with puffing quality.

Suchada Maisont and Woatthichai Narkrugsa (2010) reported the effects of salt, moisture content and microwave power on the puffing qualities of puffed rice were investigated. Paddy rice was adjusted with water and $2 \%$ salt solution at four moisture levels 10,13, 16 and 19\% (w.b) and puffed with microwave power at 600, 700 and 800 watts. The results showed that all the main factors and their interactions significantly $(\mathrm{p}<0.05)$ affected the puffing qualities of total puffed yield, fully puffed yield, small puffed yield, expansion volume, texture, color and microstructure.

\section{MATERIAL AND METHODS}

\section{Development of Small scale Rice Puffing Machine}

Based on the reviews collected on the rice puffing technology, the operational parameters considered for the development of small scale rice puffing machine are as follows.

- Blower unit for blowing the heated as well as to maintain terminal velocity of rice for exposing them throughout its surface to the heated container for rice to be get puffed.

- Heating unit for maintaining the temperature at around $200-250^{\circ} \mathrm{C}$.

- Container having slots all along its periphery at the bottom to create air current for rotating rice in order to expose them to the heated container.

- Casing to surround blower, heating unit and the container.

- Plat form to fix all the accessories of the puffing machine.

- Power transmission for transfer of electrical power from the source to the equipment.

\section{Blower Unit}

Blower unit used in the small scale rice puffing machine was comprised of electrical motor ( $0.25 \mathrm{hp})$ to which an impeller was fixed through a shaft (specially designed suit the impeller). The shaft was designed as per the requirement to get the desired air flow rate having length $105 \mathrm{~mm}$ and diameter $26 \mathrm{~mm}$. The impeller used was made up of aluminum having diameter $29 \mathrm{~mm}$ and 13 numbers of wings. Due care was taken to fix this impeller at $10 \mathrm{~cm}$ distance from heating plate placed above using cushion rods having length $35 \mathrm{~mm}$ to get desired air flow rate. The blowing unit is fixed with the heating unit using $75 \mathrm{~mm}$ length bolts and nuts. 


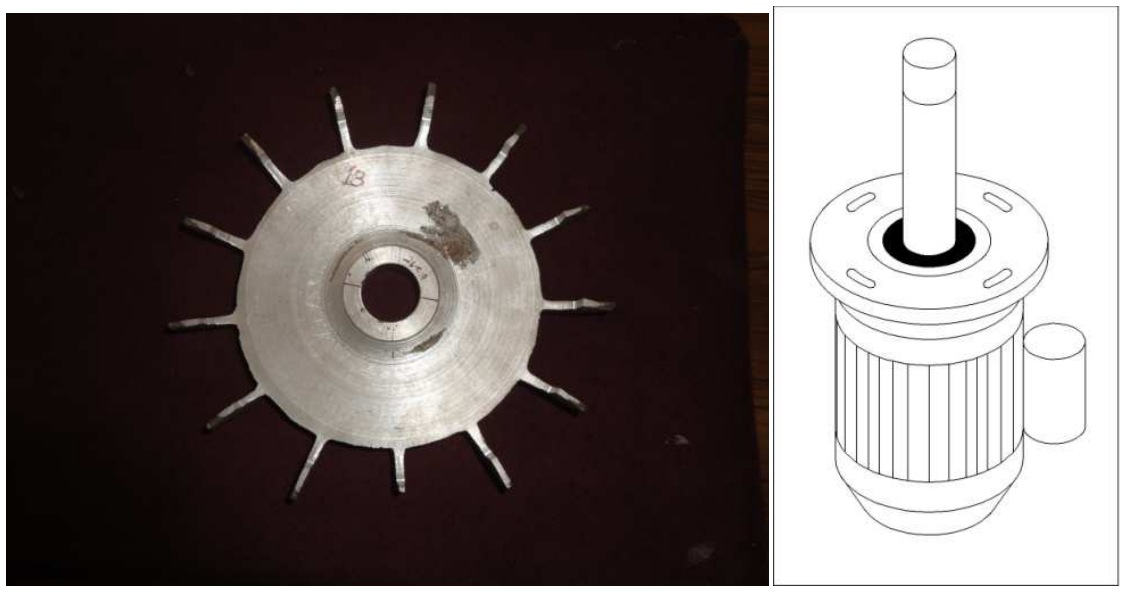

Plate 1: A View of Impeller and Motor Used as a Blowing Unit in the Puffing Machine

\section{Heating Unit}

Heating unit comprises of electrical coil made up of tungsten steel which produce three kilo watt of electric current was used. The coil having length $1000 \mathrm{~mm}$ is fixed on the circular aluminum plate of diameter 22.5. The diameter of the winding of coil used was $6.5 \mathrm{~mm}$ and is placed in a zig-zag manner through insulation material as shown in plate 2.

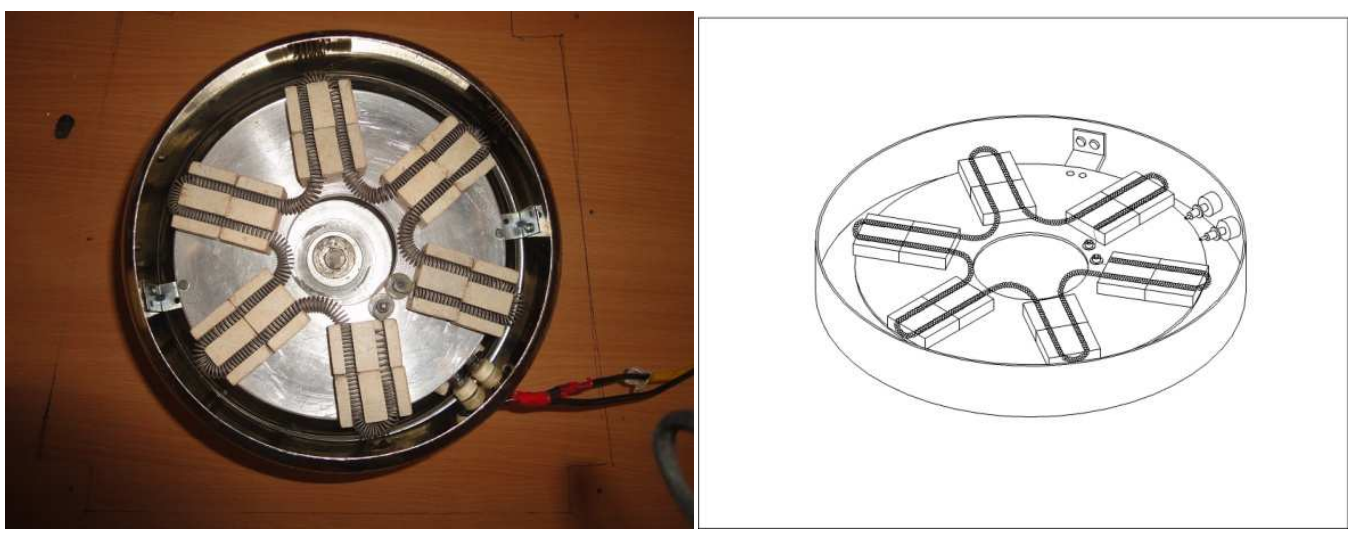

Plate 2: A View of Heating Unit Used in the Puffing Machine

\section{Container}

The container used in the puffing machine was made up of aluminium metal having diameter $295 \mathrm{~mm}$ and height $90 \mathrm{~mm}$ The flat bottom container is having capacity $5 \mathrm{~g} / \mathrm{min}$ and it has been fixed to the casing using nut and bolt (127 mm length). At the bottom of the container 35 number of slots having length $25.4 \mathrm{~mm}$ and height 27 mm was engraved all along the periphery at an interval of $15 \mathrm{~mm}$. Plate 3 . The fins formed during slot opening were bent through an angle of $35^{0}$ inward. An aluminium plate was attached to this container so as to fit this with the casing. 

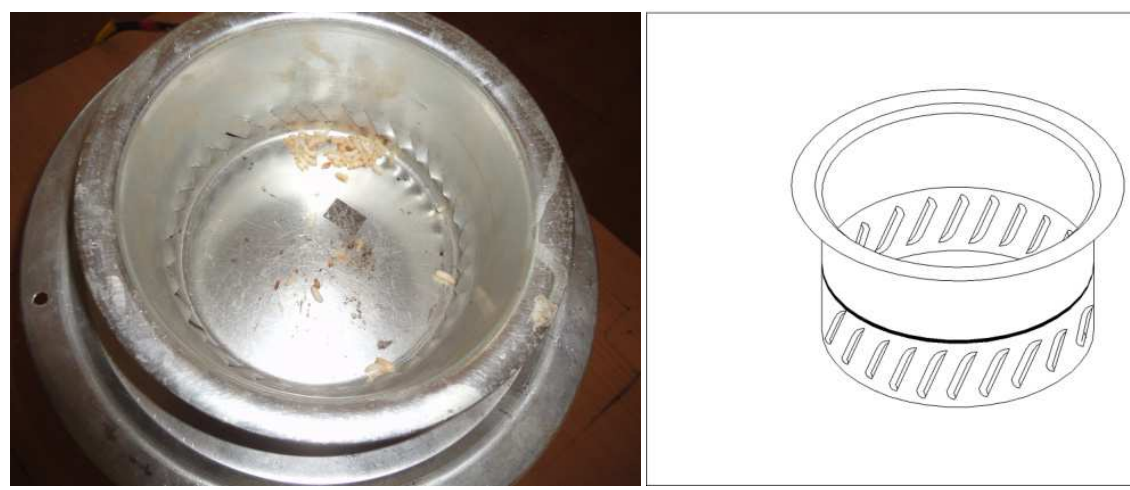

Plate 3: A View of Container Used in the Puffing Machine

\section{Casing}

The casing selected to cover the blower unit and heating unit was made up of steel material having curvature just sufficient to allow the desired air through heating coil. The casing selected was semicircular type open bowl having $75 \mathrm{~mm}$ circular hole at the bottom through which a blower shaft passed to fix an impeller. The semi circular casing is having 205 $\mathrm{mm}$ diameter and $25^{\circ}$ curvature. This was fixed to the wooden platform using four nuts. Plate 4

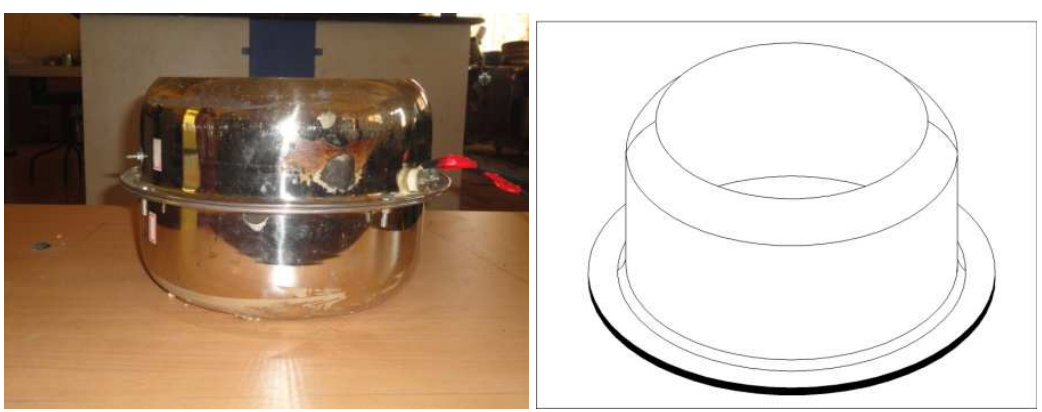

Plate 4: A View of Casing Used in the Development of Puffing Machine

\section{Wooden Platform}

The entire unit of small scale rice puffing machine was fixed exactly middle on the wooden platform made up of well seasoned wood having height $473 \mathrm{~mm}$ and width $435 \mathrm{~mm}$. Electrical motor used for blower was placed below the platform and the casing unit find the place on the upper surface. The plat form thickness of 10 mm was maintained to fix the impeller at $54 \mathrm{~mm}$ height so as to pass the desired air flow to the container. Plate 5 


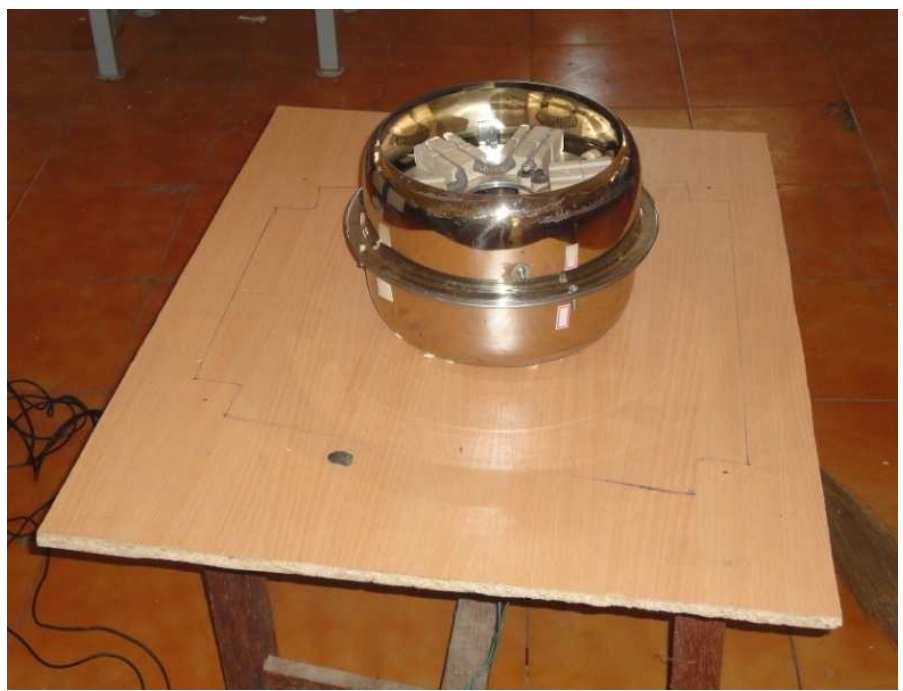

Plate 5: A View of Wooden Platform on Which Other Accessories Fitted

\section{Power Transmission}

Two types of power transmission was used in the developed machine, one from electric motor of 0.25 hp capacity operating through single phase electric power supply and the other one for heating coil connected directly to the electric source. Motor was used for blower unit for impeller rotation and the electric coil was used for heating unit. View of a complete set up is shown in the Plate 6.

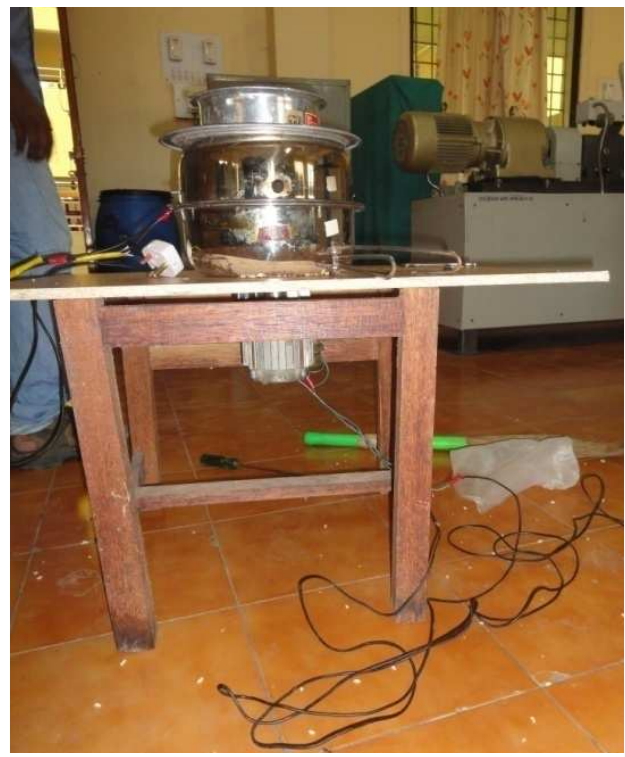

Plate 6: A View of Small Scale Rice Puffing Machine

\section{Operational Procedure of Small Scale Rice Puffing Machine}

The assembly of different accessories of small rice puffing machine include, blower unit, heating unit, container and casing. All were fitted on the wooden platform as shown in plate 6

The developed small scale rice puffing machine operates through two power sources. The one which is used to run the motor $(0.25 \mathrm{hp})$ fitted to the impeller for getting desired rpm and the other source was the external electrical power source to heat the coil for getting desired temperature. Some of the operational parameter considered for rice puffing from 
the developed machine was as follows.

- Impeller speed, rpm

- Heating temperature, ${ }^{0} \mathrm{C}$

- Container design,

- Casing design

The development of rice puffing machine was done by keeping the optimum operational parameters of rice puffing technology. The Motor and the impeller was selected/designed so as to get the desired air velocity to roll force the rice placed in the container to run all along periphery for getting maximum area exposed to the heat source. The container design was also aimed for proper size and shape of slots so as to get the desired air flow through the slots for moving the rice placed in the container.

After switching on the electrical heating source wait for some time till getting desired conduction heating temperature of the container and then the blower unit has to be switched on. When the conditioned rice is placed in the container, the rice will get puffed with in specified time and comes out of the container.

\section{Conditioning of Rice before Used for Puffing in Rice Puffing Machine}

Conditioning of rice prior to the puffing operation is an essential requirement for getting puffed rice. The rice conditioning process flow chart adopted during the study is presented below.

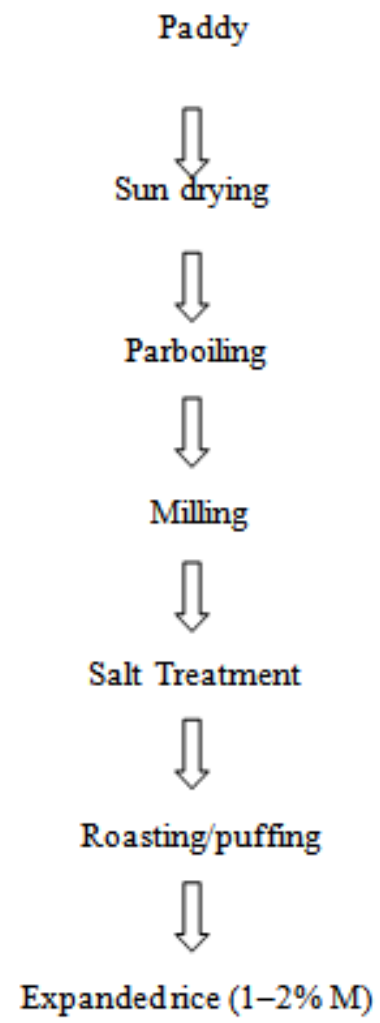

Figure 1: Process Flow Chart for Conditioning of Rice 


\section{Performance Evaluation of Machine}

The designed and fabricated machine was tested to evaluate its performance on the basis of its capacity and puffing quality. The puffing capacity of the machine was determined by feeding the conditioned rice in to container to puff it within a period of minute and then the puffed rice was weighed in order to determine the capacity and puffing quality.

\section{RESULTS AND DISCUSSIONS}

\section{Puffing Quality}

The results of the parameters considered under puffing quality of puffed rice are as follows.

Taste

The general acceptance of consumer for regular usage is considered in respect of taste. It was found that no significant difference was noticed with respect to taste. Taste is mainly characterized by the quantity of salt solution used and the stickiness during mouth feel.

\section{Expansion Ratio}

The expansion ratio observed for IR-64 rice variety which is normally used in Raichur for both the methods are almost similar. The expansion ratio of the IR 64 was observed as 12.5.The expansion volume of puffed rice soaked in salt solution was more as compared to rice soaked in tap water. The expansion volume of puffed rice was higher when the moisture content increased from 10 to 13\%, but was lower when the moisture content was 16 and19 \% (Suchada et al., 2010). Expansion ratio of puffed rice is influenced by the amylase content of rice, salt solution treatment and the lengthwidth ratio. As the length width-width ratio increases, the expansion ratio also increases. Higher the amylase content in the rice influenced the higher expansion ratio.

\section{Product Hygienic Condition}

The product hygiene observed for the puffed rice obtained from both the methods were observed. It was found that the dissolved solids obtained after soaking of puffed rice from manual method is less as compared to mechanical method. This may be due to exposure of puffed rice to a high degree of dust generated during pressure feeding of saw-dust in mechanical rice puffing methods.

\section{Storage Life}

As per the consumers of puffed rice opinion the storage life prepared from both the methods i.e manual and mechanical methods was about 2 months with respect to crispiness and cooking quality is concerned. Some of the quality parameters of the puffed rice are presented in table.

Table 1: Evaluation Parameters of Small Scale Rice Puffing Machines

\begin{tabular}{|l|c|}
\hline \multicolumn{1}{|c|}{ Description } & $\begin{array}{c}\text { Small Scale Puffing } \\
\text { Machine }\end{array}$ \\
\hline Capacity & $5 \mathrm{~kg} /$ day $(5 \mathrm{~h})$ \\
\hline Labour requirement & 1 \\
\hline Temperature in puffing & $220-250^{0} \mathrm{C}$ \\
\hline Expansion ratio of rice & 9.4 \\
\hline Storage life & 2 months \\
\hline
\end{tabular}




\section{CONCLUSIONS}

This machine is simple in construction and easy to operate. The capacity of the small scale rice puffing machine ranges between $4-5 \mathrm{~kg} / \mathrm{h}$. One labor is enough for operation of machine as well as other activities. The drudgery involved during operation was almost nil as compared to traditional rice puffing methods. With respect to environmental safety concern, the puffing operation from small scale rice puffing machine was completely safe because it uses electric power source and no emittance of any harmful gases.

\section{REFERENCES}

1. Chandrasekhar, P.R. and Chattopadhyay, P.K, (1988), Heat transfer during fluidized bed puffing of rice grains, Journal of Food Process Engineering, 11:147-157.

2. Suchada Maisont and Woatthichai Narkrugsa, (2010), Effects of salt, moisture content and microwave power on puffing qualities of puffed rice, Kasetsart J. (Nat. Sci.) 44:251 - 261.

3. Malleshi,N.G. and Desikachar, H.S.R,(1981), Varietal differences in puffing quality of ragi (Elusine coracana). Journal of Food Science and Technology, 26: 26-28. 